\title{
ECO GREEN PARK BATU
}

\author{
Linda Ayu Wibriana \\ Department of Management \\ E-mail:Wellandha@yahoo.com
}

\begin{abstract}
This study is based on the importance of service quality on the company. This meant that all the goods and services offered will have a good place in the eyes of the public as consumers and potential consumers. Although relatively new company, but the importance of service quality mak the company is trying to get customers as possible by providing services and facilities. The purpose of this study is to analyze quality of service in the Physical dimension (Tangible), reliability, Responsiveness, Assurance, and Empathy on ECO Green Park Batu city. The population in this study are visitor. Total sample of 100 people, with a quota sampling technique and using a questionnaire for data collection. Analyses data using frequency distribution and analysis tools using servqual and Cartesian diagram. The results showed that the A quadrant is a main priority of the counter clerk service providing quickly. Kuadran B or maintain achievement, factors that include the access road to the Park is easy, has a large parking lot, the company providing the information right, the right service / satisfaction of the officer, the company provide information in a clear, swift cleaning service clean the tourist area, safety guard officers ready to serve. Quadrant $C$ or low priority that the appropriate services / satisfaction of the officer, the officer has a vast knowledge when they explain to visitors officials are consistently polite, serving officers earnestly and wholeheartedly, giving service to all visitors without picky, ease of conveying suggestions / complaints. Quadrant D or excessive such factors which include building which attractive, employees have a neat appearance, complete public facilities, reliable officer in operating a vehicle. Seeing this is not a problem if the company providing the service excessively, because it feels it is able to make visitors feel satisfied.
\end{abstract}

Keywords: Quality of Service, tangible, in tangible

\section{PENDAHULUAN}

Kualitas jasa berkaitan erat dengan kepuasan pelanggan. Hal ini dimaksudkan agar semua barang dan jasa yang ditawarkan akan mendapat tempat yang baik di mata masyarakat selaku konsumen dan calon konsumen. Tidak dipungkiri perusahaan berlomba-lomba untuk mendapatkan konsumen sebanyak mungkin dengan memberikan jasa dan fasilitas pelayanan yang maksimal, maka dari itu hal-hal yang berhubungan dengan konsumen harus diperhatikan. Pelanggan umumnya mengharapkan barang atau jasa yang ia konsumsi dapat diterima atau dinikmatinya dengan pelayanan 
yang baik atau memuaskan. Dengan perkataan lain para pelanggan menginginkan mutu pelayanan yang diberikan adalah baik dan memuaskan. Perusahaan harus memperhatikan mutu dari jasa (service quality) dan pelayanan yang diberikan oleh perusahaannya. Dalam hal ini perusahaan tentunya berupaya untuk memberikan jasa (service quality) yang baik kepada pelanggannya. Hal ini merupakan upaya perusahaan untuk dapat tampil bedanya perusahaan tersebut dengan para pesaingnya.

Indonesia merupakan salah satu negara yang memiliki banyak tempat-tempat wisata. Potensi inilah yang terus menerus dikembangkan. Menurut Undang-undang nomor 9 Tahun 1990 tentang Kepariwisataan Bab 1 Pasal 1 dinyatakan bahwa wisata adalah kegiatan perjalanan atau sebagian dari kegiatan tersebut yang dilakukan secara sukarela dan bersifat sementara untuk menikmati objek dan daya tarik wisata.

Pada pariwisata wilayah Jawa Timur tepatnya Malang, terdapat beberapa tempat wisata yang cukup berkembang, misalnya Selekta, Sengkaling, BNS, Museum Satwa dan Batu Secret Zoo, selain beberapa tempat wisata tersebut Jawa Timur Park 2 kini memiliki objek wahana baru lagi yang bernama ECO Green Park. ECO Green Park berdiri pada tanggal 10 Juli 2012. Objek Wisata ECO Green Park sendiri berlokasi 1 tempat dengan Jawa Timur Park 2 yang terletak di Jl.Oro-oro Ombo No 9A, Batu. ECO Green Park ini adalah tempat wisata baru di susun dengan konsep "Fun and Study" yaitu pembelajaran atau edukasi dengan nuansa alam yang berisi tentang ekosistem, permainan, dimana pengunjung akan diajak untuk melihat koleksi binatang dan tanaman serta bagaimana cara kita menjaga lingkungan melalui edukasi langsung maupun teknologi visual dengan konsep yang menyenangkan, dengan demikian selain berwisata kita juga sekaligus bisa belajar. ECO Green Park juga menghadirkan wahana lainnya seperti Hydroponic, Eco journey, Insectarium, Dome multimedia, Music Plaza, Rumah terbalik dan beragam wahana lainnya yang didukung sepenuhnya oleh PLN, Telkom, dan PT. Bungawangsa sejati.

Rumusan masalah dalam penelitian ini yaitu Bagaimana kualitas pelayanan dalam dimensi Fisik (Tangible), Kehandalan (Reliability), Tanggapan (Responsiveness), Kepastian (Assurance), dan Empati (Empathy) ECO Green Park Batu? Hasil penelitian yang digunakan sebagai dasar secara empiris yaitu dalam menentukan variabel-variabel yang akan dipergunakan, maka peneliti saat ini mengambil dasar penelitian terdahulu yg dilakukan oleh Dendi Dwi Sukmawan (2006). Persamaan dari penelitian terdahulu dengan sekarang adalah pada kesamaan variabel yang digunakan..

Variabel kedua penelitian diatas diambil dari Metode Servqual milik Parasuraman, yaitu Bukti fisik (Tangible), Kehandalan (Reliability), Daya tanggap (Responsiveness), Jaminan (Assurance), Empati (Empathy), selain itu objek penelitian juga sama yaitu sama-sama menggunakan objek wisata. Sedangkan perbedaannya terdapat pada alat analisis yang digunakan. 
Pada penelitian terdahulu menggunakan alat analisis Structural Equation Modelling sedangkan pada

\section{TINJAUAN PUSTAKA}

Menurut Gronroos (1992) jasa adalah proses yang terdiri atas serangkaian aktifitas intangible yang biasanya (namun tidak harus selalu) terjadi pada interaksi antara pelanggan dan karyawan jasa dan atau sumber daya fisik atau barang dan atau system penyedia jasa, yang disediakan sebagai solusi atas masalah pelanggan. Lovelock (2005) mengartikan jasa adalah tindakan yang menciptakan manfaat bagi pelanggan dengan mewujudkan perubahan yang diinginkan dalam diri atau atas nama penerima. Jadi dapat disimpulkan bahwa jasa adalah suatu proses aktivitas intangible yang ditawarkan suatu pihak ke pihak lainnya.

Menurut Lovelock dan Wright (2005) menyatakan kualitas jasa didasarkan pada evaluasi kognitif jangka panjang terhadap penyerahan jasa perusahaan. Jadi, kualitas jasa ialah tingkat keunggulan yang diharapkan dan pengendalian atas tingkat keunggulan tersebut untuk memenuhi keinginan pelanggan.

Penelitian sebelumnya mengidentifikasi 10 dimensi pokok, yakni reliabilitas, daya tanggap, kompetensi, akses, kesopanan, komunikasi, kredibilitas, keamanan, kemampuan memahami pelanggan, dan bukti fisik. Namun penelitian berikutnya Parasuraman et., all (1988), menemukan ada lima penentu kualitas jasa, yaitu : a) Reliability: kemampuan untuk memberikan jasa dengan segera penelian saat ini menggunakan alat analisis Metode Servqual dan Diagram Kartesius.

dan memuaskan. b) Responsiveness: kemampuan untuk memberikan jasa dengan tanggap. c) Assurance: kemampuan, kesopanan, dan sifat dapat dipercaya yang dimiliki oleh para staf, bebas dari bahaya, resiko dan keragu-raguan. d) Emphaty: kemudahan dalam melakukan hubungan komunikasi yang baik dan memahami kebutuhan pelanggan. e) Tangibles: fasilitas fisik, perlengkapan, pegawai dan sarana komunikasi.

Model kualitas jasa yang popular dan hingga kini banyak dijadikan acuan dalam riset pemasaran adalah model Servqual (Service Quality) (Tjiptono, 2007). Model yang dikembangkan oleh Parasuraman, Zeithaml, dan Bery mempresentasikan kualitas jasa sampai pada tahap mekanismemenentukan factor-faktor yang mempengaruhi penilaian terhadap kualitas jasa dan interaksi terhadap penyedia jasa dan pelanggannya.

Model ini mengajukan bahwa suatu jasa yang ditawarkan berasalkan dari persepsi manajemen atas ekspetasi konsumennya. Kemudian persepsi manajemen ini didesain menjadi spesifikasi kualitas tertentu dan disampaikan kepada pelanggan melalui layanan ataupun komunikasi eksternal, interaksi antara penyedia dan pelanggan jasa ini akan menimbulkan persepsi pelanggan atas jasa yang diterimanya. Persepsi ini yang akan dibandingkan pelanggan terhadap ekpektasi. Berdasarkan teori yang 
telah dikemukakan maka kerangka pikir dalam penelitian ini dapat Berdasarkan landasan teori yang telah disusun di atas, maka pada gambar 1 dapat dijelaskan bahwa melalui variable bukti fisik, kehandalan, daya tanggap, jaminan dilihat pada Gambar 1.

serta empati dapat diukur suatu kualitas pelayanan suatu perusahaan dapat dikategorikan kedalam kualitas layanan yang baik atau buruk.

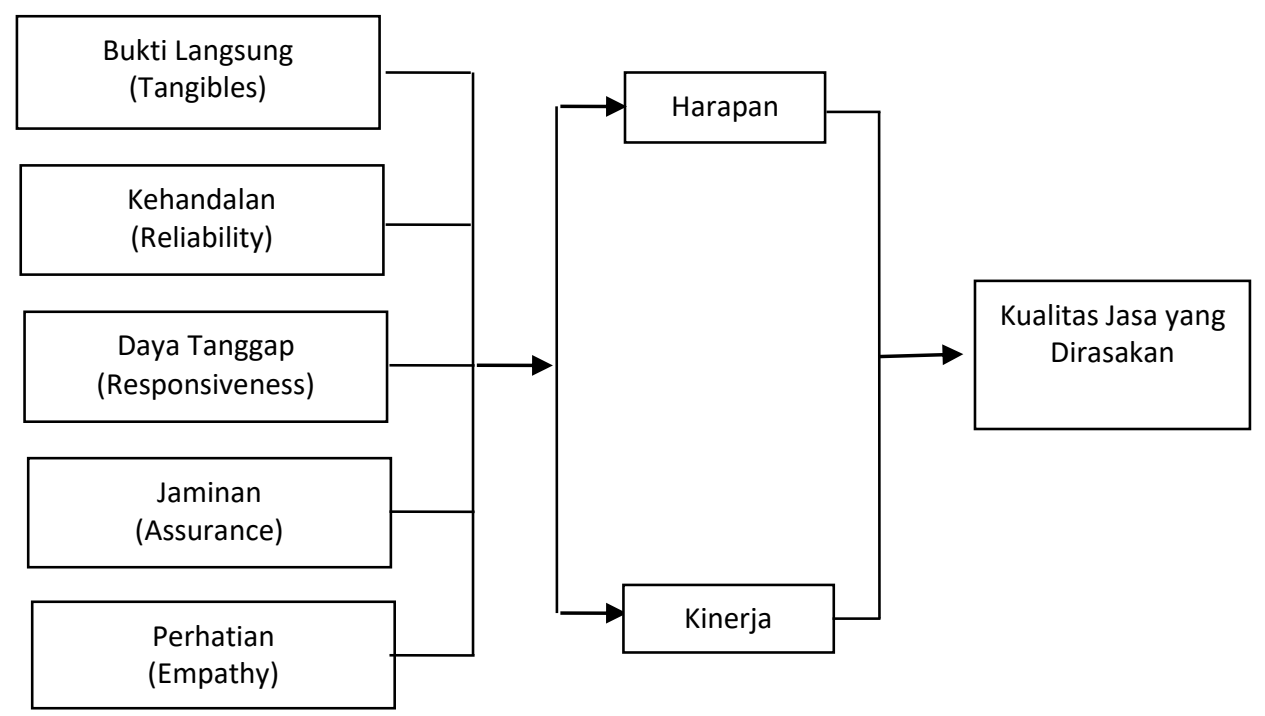

Gambar 1. Kerangka Pikir Penelitian Analisis Kualitas Layanan ECO Green Park

\section{METODE PENELITIAN}

Jenis penelitian yang digunakan adalah penelitian kuantitatif deskriftif, yaitu penelitian yang menjelaskan permasalahan yang akan diteliti (Widayat, 2004). Dalam penelitian ini, data dikumpulkan dengan metode survey dimana nantinya peneliti akan menggunakan kuisioner terstruktur yang berisi pertanyaan-pertanyaan untuk menggali informasi dari pengunjung ECO Green Park

Dalam suatu penelitian harus disebutkan dari mana data diperoleh sebagaimana yang telah dinyatakan oleh Arikunto (2002). Sumber data adalah subjek darimana data diperoleh. Di dalam penelitian ini data yang digunakan di bagi dua bagian. Menurut Indriantoro dan
Supomo (2002) sumber data dibagi menjadi dua yaitu:1) Data Primer, data primer adalah data yang dibuat oleh peneliti dengan maksud khusus dalam menyeleseikan masalah riset (Malhotra, 2005).

Data primer merupakan data yang diperoleh langsung oleh peneliti tanpa melalui perantara. Dalam hal ini, data primer didapat dari hasil jawaban responden melalui kuisioner yang telah diberikan. 2) Data Sekunder, data sekunder adalah data yang dikumpulkan untuk maksud selain menyeleseikan masalah yang dihadapi (Malhotra, 2005) yaitu data yang mendukung kelengkapan penelitian ini yaitu dari internet, media cetak, penelitian terdahulu serta dokumentasi dari pihak ECO Green Park itu sendiri. 
Adapun dalam penelitian ini yang menjadi populasi adalah pengunjung pada objek wisata ECO Green Park Malang. Teknik pengambilan sampel yang digunakan dalam penelitian ini yaitu menggunakan tekhnik nonprobability sampling, dengan jumlah sampel sebanyak 100 responden. Teknik analisis data yaitu menggunakan metode pengukuran kualitas layanan yang banyak digunakan secara luas adalah metode SERVQUAL. Metode SERVQUAL dibangun atas adanya perbandingan dua faktor utama yaitu persepsi pelanggan atas layanan yang nyata mereka terima (perceived service) dengan layanan yang sesungguhnya diharapkan oleh pelanggan (expected service) dan diagram kartesius.

\section{HASIL PENELITIAN DAN PEMBAHASAN}

Berdasarkan data diatas dapat disusun nilai rata-rata antara harapan responden dan kinerja perusahaan ECO Green Park Batu serta dapat disajikan pula data Servqual yang dapat dilihat pada tabel 1.

Dari tabel 1 dapat diketahui bahwa pada indikator akses jalan menuju ECO Green Park $\operatorname{mudah}\left(\mathrm{X}_{1.1}\right)$ menunjukkan skor servqual yang diperoleh sebesar 0,21 atau positif, dengan kata lain kinerja yangdilakukan oleh pihak perusahaansudah baik atau melebihi harapan

Tabel 1. Rata-Rata Hasil Harapan dan Kinerja

\begin{tabular}{|c|c|c|c|}
\hline Indikator & $\begin{array}{c}\text { Skor } \\
\text { Harapan }\end{array}$ & $\begin{array}{l}\text { Skor } \\
\text { Kinerja }\end{array}$ & $\begin{array}{c}\text { Skor } \\
\text { Servqual }\end{array}$ \\
\hline Akses jalan menuju ECO Green Park mudah $\left(\mathrm{X}_{1.1}\right)$ & 3,7 & 3,91 & 0,21 \\
\hline $\begin{array}{l}\text { ECO Green Park memiliki lapangan parkir yang } \\
\text { luas }\left(\mathrm{X}_{1.2}\right)\end{array}$ & 3,69 & 3,86 & 0,17 \\
\hline $\begin{array}{l}\text { Gedung dan bangunan ECO Green Park menarik } \\
\left(\mathrm{X}_{1.3}\right)\end{array}$ & 3,66 & 3,96 & 0,3 \\
\hline Karyawan memiliki penampilan rapi $\left(\mathrm{X}_{1.4}\right)$ & 3,68 & 4,07 & 0,39 \\
\hline Fasilitas umum ECO Green Park lengkap $\left(\mathrm{X}_{1.5}\right)$ & 3,65 & 3,98 & 0,33 \\
\hline $\begin{array}{l}\text { Perusahaan memberikan informasi dengan tepat } \\
\left(\mathrm{X}_{2.1}\right)\end{array}$ & 3,7 & 4,01 & 0,31 \\
\hline $\begin{array}{l}\text { Pelayanan yang tepat/ memuaskan oleh petugas } \\
\left(\mathrm{X}_{2.2}\right)\end{array}$ & 3,7 & 4 & 0,3 \\
\hline Petugas mampu berkomunikasi dengan baik $\left(\mathrm{X}_{2.3}\right)$ & 3,67 & 3,75 & 0,08 \\
\hline $\begin{array}{l}\text { Petugas handal dalam mengoperasikan wahana } \\
\left(\mathrm{X}_{2.4}\right)\end{array}$ & 3,64 & 3,9 & 0,26 \\
\hline Perusahaan memberikan informasi secara jelas $\left(\mathrm{X}_{3.1}\right)$ & 3,77 & 3,96 & 0,19 \\
\hline $\begin{array}{l}\text { Petugas loket memberikan pelayanan secara cepat } \\
\left(\mathrm{X}_{3.2}\right)\end{array}$ & 3,77 & 3,79 & 0,02 \\
\hline $\begin{array}{l}\text { Petugas cleanning service sigap membersihkan area } \\
\text { wisata }\left(\mathrm{X}_{3.3}\right)\end{array}$ & 3,76 & 3,86 & 0,1 \\
\hline Petugas safetyguard siap melayani $\left(\mathrm{X}_{4.1}\right)$ & 3,79 & 3,96 & 0,17 \\
\hline Petugas memiliki pengetahuan luas $\left(\mathrm{X}_{4.2}\right)$ & 3,61 & 3,69 & 0,08 \\
\hline Petugas secara konsisten bersikap sopan $\left(\mathrm{X}_{4.3}\right)$ & 3,65 & 3,63 & $-0,02$ \\
\hline Petugas melayani dengan sungguh-sungguh $\left(\mathrm{X}_{5.1}\right)$ & 3,61 & 3,71 & 0,1 \\
\hline $\begin{array}{l}\text { Pelayanan terhadap semua pengunjung tanpa pilih- } \\
\text { pilih }\left(\mathrm{X}_{5.2}\right)\end{array}$ & 3,62 & 3,67 & 0,05 \\
\hline Kemudahan menyampaikan saran/ keluhan $\left(\mathrm{X}_{5.3}\right)$ & 3,59 & 3,66 & 0,07 \\
\hline Rata-Rata & 3,681 & 3,855 & \\
\hline
\end{tabular}


pengunjung. Pada indikator ECO Green Park memiliki lapangan parkir yang luas $\left(\mathrm{X}_{1.2}\right)$ menunjukkan skor servqual yang diperoleh sebesar 0,17 atau positif, dengan kata lain kinerja yang dilakukan oleh pihak perusahaan sudah baik atau melebihi harapan pengunjung.

Pada indikator Gedung dan bangunan ECO Green Park menarik $\left(\mathrm{X}_{1.3}\right)$ menunjukkan skor servqual yang diperoleh sebesar 0,3 atau positif, dengan kata lain kinerja yang dilakukan oleh pihak perusahaan sudah baik atau melebihi harapan pengunjung. Pada indikator karyawan memiliki penampilan $\operatorname{rapi}\left(\mathrm{X}_{1.4}\right)$ menunjukkan skor servqual yang diperoleh sebesar 0,39 atau positif, dengan kata lain kinerja yang dilakukan oleh pihak perusahaan sudah baik atau melebihi harapan pengunjung. Pada indikator fasilitas umum ECO Green Park lengkap $\left(\mathrm{X}_{1.5}\right)$ menunjukkan skor servqual yang diperoleh sebesar 0,33 atau positif, dengan kata lain kinerja yang dilakukan oleh pihak perusahaan sudah baik atau melebihi harapan pengunjung.

Pada indikator perusahaan memberikan informasi dengan tepat $\left(\mathrm{X}_{2.1}\right)$ menunjukkan skor servqual yang diperoleh sebesar 0,31 atau positif, dengan kata lain kinerja yang dilakukan oleh pihak perusahaan sudah baik atau melebihi harapan pengunjung. Pada indikator pelayanan yang tepat / memuaskan oleh petugas $\left(\mathrm{X}_{2.2}\right)$ menunjukkan skor servqual yang diperoleh sebesar 0,3 atau positif, dengan kata lain kinerja yang dilakukan oleh pihak perusahaan sudah baik atau melebihi harapan pengunjung. Pada indikator petugas mampu berkomunikasi dengan baik $\left(\mathrm{X}_{2.3}\right)$ menunjukkan skor servqual yang diperoleh sebesar 0,08 atau positif, dengan kata lain kinerja yang dilakukan oleh pihak perusahaan sudah baik atau melebihi harapan pengunjung. Pada indikator petugas handal dalam mengoperasikan wahana $\left(\mathrm{X}_{2.4}\right)$ menunjukkan skor servqual yang diperoleh sebesar 0,26 atau positif,dengan kata lain kinerja yang dilakukan oleh pihak perusahaan sudah baik atau melebihi harapan pengunjung.

Pada indikator perusahaan memberikan informasi secara jelas $\left(\mathrm{X}_{3.1}\right)$ menunjukkan skor servqual yang diperoleh sebesar 0,19 atau positif, dengan kata lain kinerja yang dilakukan oleh pihak perusahaan sudah baik atau melebihi harapan pengunjung. Pada indikator petugas loket memberikan pelayanan secara cepat $\left(\mathrm{X}_{3.2}\right)$ menunjukkan skor servqual yang diperoleh sebesar 0,02 atau positif, dengan kata lain kinerja yang dilakukan oleh pihak perusahaan sudah baik atau melebihi harapan pengunjung.Pada indikator petugas cleaning service sigap membersihkan area wisata $\left(\mathrm{X}_{3.3}\right)$ menunjukkan skor servqual yang diperoleh sebesar 0,1 atau positif, dengan kata lain kinerja yang dilakukan oleh pihak perusahaan sudah baik atau melebihi harapan pengunjung.

Pada indikator petugas safetyguard siap melayani $\left(\mathrm{X}_{4.1}\right)$ menunjukkan skor servqual yang diperoleh sebesar 0,17 atau positif, dengan kata lain kinerja yang dilakukan oleh pihak perusahaan sudah baik atau melebihi harapan pengunjung. Pada indikator petugas memiliki pengetahuan luas ketika mereka menjelaskan kepada pengunjung seputar ECO Green Park $\left(\mathrm{X}_{4.2}\right)$ menunjukkan skor servqual yang diperoleh sebesar 0,08 atau positif, dengan kata lain kinerja yang dilakukan oleh pihak perusahaan sudah baik atau melebihi harapan pengunjung.

Pada indikator petugas secara konsisten bersifat sopan $\left(\mathrm{X}_{4.3}\right)$ menunjukkan skor servqual yang diperoleh sebesar 0,02 atau negatif, dengan kata lain kinerja yang dilakukan oleh pihak perusahaan belum mampu memenuhi 
harapan pengunjung. Pada indikator petugas melayani dengan sungguhsungguh dan sepenuh hati $\left(\mathrm{X}_{5.1}\right)$ menunjukkan skor servqual yang diperoleh sebesar 0,1 atau positif, dengan kata lain kinerja yang dilakukan oleh pihak perusahaan sudah baik atau melebihi harapan pengunjung. Pada indikator pemberian pelayanan terhadap semua pengunjung tanpa pilih-pilih ( $\left.\mathrm{X}_{5.2}\right)$ menunjukkan skor servqual yang diperoleh sebesar 0,05 atau positif, dengan kata lain kinerja yang dilakukan oleh pihak perusahaan sudah baik atau melebihi harapan pengunjung.

$$
\text { Pada indikator kemudahan }
$$

menyampaikan saran / keluhan ( $\left.\mathrm{X}_{5.3}\right)$ menunjukkan skor servqual yang diperoleh sebesar 0,07 atau positif, dengan kata lain kinerja yang dilakukan oleh pihak perusahaan sudah baik atau melebihi harapan pengunjung.Dari data tersebut dapat diketahui bahwa kinerja petugas sudah baik dan semua indikator sudah memenuhi harapan konsumen hal ini bisa dilihat dari jasa yang dirasakan, serta nilai rata-rata servqual yang menunjukkan hasil positif dari keseluruhan variabel, namun ada satu item variabel yakni mengenai petugas secara konsisten bersifat sopan $\left(\mathrm{X}_{4.3}\right)$ menunjukkan hasil negatif, kondisi ini berarti menunjukkan bahwa selama ini pelayanan yang diberikan oleh petugas dirasakan belum memenuhi harapan pengunjung.

Berdasarkan nilai rata-rata tersebut maka dapat disusun diagram kartesius yang terbagi menjadi empat bagian yaitu prioritas utama, pertahankan prestasi, prioritas rendah dan berlebihan. Adapun diagram kartesius analisis kualitas jasa pada obyek wisata ECO Green Park Batu dapat dilihat pada Gambar 2.

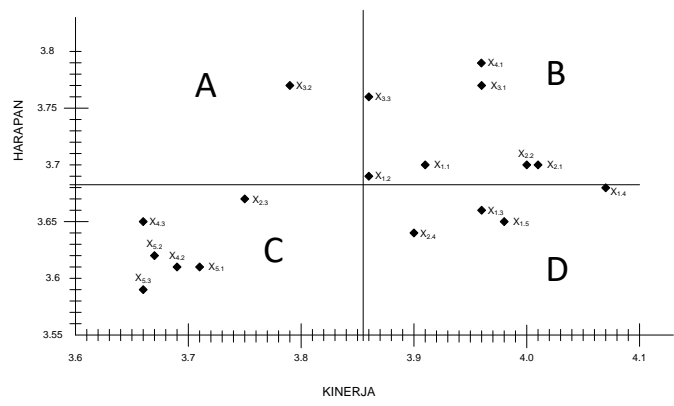

Gambar 2. Gambar Digram Kartesius dari Analisis Kualitas Jasa Wisata ECO Green Park Batu

Berdasarkan gambar diagram kartesius diatas maka masing-masing kuandran dapat diuraikan sebagai berikut: Kuadran A : Petugas loket memberikan pelayanan secara cepat $\left(\mathrm{X}_{3.2}\right)$. Hasil analisis pada kuadran A yakni prioritas utama ini dapat diketahui bahwa selama ini pengelola ECO Green Park belum memberikan jaminan atas kepuasan kepada pelanggan, dimana faktor tersebut menjadi faktor yang penting menurut pelanggan namun pihak manajemen belum memaksimalkan sesuai dengan keinginan pelanggan. Faktor tersebut yaitu mengenai petugas loket memberikan pelayanan secara cepat. Kondisi ini menjadikan pengunjung belum mendapatkan kepuasan secara maksimal sehingga pengunjung merasakan adanya ketidak puasan pada faktor tersebut. Dengan demikian upaya yang seharusnya dilakukan oleh perusahaan adalah dapat menambah jumlah loket yang sudah ada, dan bisa juga melatih karyawan agar bisa bekerja/ melayani dengan cepat.

Kuadran B: a)Akses jalan menuju ECO Green Park mudah $\left(\mathrm{X}_{1.1}\right)$. b) ECO Green Park memiliki lapangan parkir yang luas $\left(X_{1.2}\right)$. c) Perusahaan memberikan informasi dengan tepat $\left(\mathrm{X}_{2.1}\right)$. d) Pelayanan yang tepat / memuaskan oleh petugas $\left(X_{2.2}\right)$. e) Perusahaan memberikan informasi secara jelas $\left(\mathrm{X}_{3.1}\right)$. f) Petugas cleaning service sigap membersihkan area wisata $\left.\left(\mathrm{X}_{3.3}\right) . \mathrm{g}\right)$ Petugas safetyguard siap melayani $\left(\mathrm{X}_{4.1}\right)$. 
Pada kuadran kedua atau pertahankan prestasi, faktor-faktor yang memberikan jaminan atau dukungan dalam memberikan kepuasan pelanggan yaitu meliputi akses jalan menuju ECO Green Park mudah, ECO Green Park memiliki lapangan parkir yang luas, perusahaan memberikan informasi dengan tepat, pelayanan yang tepat / memuaskan oleh petugas, perusahaan memberikan informasi secara jelas, petugas cleaning service sigap membersihkan area wisata, petugas safetyguard siap melayani.

Berbagai bentuk pelayanan dan fasilitas tersebut memberikan jaminan atau dukungan dalam upaya memaksimalkan kepuasan kepada pengunjung, dimana selama ini pengunjung merasa puas atas fasilitas dan pelayanan yang diberikan serta pihak manejemen mampu memenuhi keianginan konsumen. Kondisi ini menjadikan perusahaan harus mampu mempertahankan atas fasilitas yang ditawarkan sehingga kepuasan konsumen tetap terjaga.

Kuadran C: a) Petugas mampu berkomunikasi dengan baik $\left(\mathrm{X}_{2.3}\right)$. b) Petugas memiliki pengetahuan luas ketika mereka menjelaskan kepada pengunjung seputar ECO Green Park $\left(\mathrm{X}_{4.2}\right)$. c) Petugas secara konsisten bersifat $\operatorname{sopan}\left(\mathrm{X}_{4.3}\right)$. d) Petugas melayani dengan sungguhsungguh dan sepenuh hati $\left(\mathrm{X}_{5.1}\right)$. e) Pemberian pelayanan terhadap semua pengunjung tanpa pilih-pilih $\left(\mathrm{X}_{5.2}\right)$. $\mathrm{f}$ ) Kemudahan menyampaikan saran / $\operatorname{keluhan}\left(\mathrm{X}_{5.3}\right)$.

Pada kuadran ketiga atau prioritas rendah yakni mengenai pelayanan yang tepat/memuaskan oleh petugas, petugas memiliki pengetahuan luas ketika mereka menjelaskan kepada pengunjung seputar ECO Green Park, petugas secara konsisten bersifat sopan, petugas melayani dengan sungguh-sungguh dan sepenuh hati, pemberian pelayanan terhadap semua pengunjung tanpa pilih-pilih, kemudahan menyampaikan saran / keluhan.
Pada faktor pelayanan yang diberikan oleh perusahaan selama ini para pengunjung tidak terlalu mempertimbangkan atas kualitas pelayanan pada faktor tersebut dan pengunjung juga merasa tidak merasa puas. Pada kuadran ini pengunjung tidak terlalu memperhatikan atau mempertimbangkan atas kualitas pelayanan pada kuadran ketiga, dimana dengan tidak maksimalnya kuadran ini tidak menyebabkan pengunjung merasa dirugikan atau tidak puas.Karyawan memiliki penampilan rapi $\left(\mathrm{X}_{1.4}\right)$. c)Fasilitas umum ECO Green Park lengkap $\left(\mathrm{X}_{1.5}\right)$. d) Petugas handal dalam mengoperasikan wahana $\left(\mathrm{X}_{2.4}\right)$.

Pada kuadran keempat atau berlebihan disini pihak manajemen ECO Green Park terlalu memperhatikan fasilitas pada kuadran ini namun demikian keberadaannya tidak terlalu menjadi pertimbangan bagi pengunjung walaupun perusahaan memberikan pelayanan yang terlalu berlebihan. Faktot tersebut yaitu meliputi gedung dan bangunan ECO Green Park menarik, karyawan memiliki penampilan rapi, fasilitas umum ECO Green Park lengkap, petugas handal dalam mengoperasikan wahana. Walaupun pelaksanaannya berlebihan dan kurang penting tetapi hal ini justru membuat pengunjung merasa puas. Melihat hal tersebut tidak menjadi masalah jika perusahaan memberikan pelayanan yang berlebihan, malah seharusnya dipertahankan karena hal ini sudah cukup baik dan dirasa justru mampu membuat pengunjung merasa puas.

Hasil penelitian ini didukung oleh teori model servqual (service quality) oleh Tjiptono (2007), dimana model ini mengajukan bahwa suatu jasa yang ditawarkan berasalkan dari persepsi manajemen atas ekspektasi konsumennya. Kemudian persepsi manajemen ini di desain menjadi spesifikasi kualitas tertentu yang nantinya akan disampaikan kepada 
pelanggan melalui layanan maupun komunikasi, interaksi antara penyedia dan pelanggan jasa ini akan menimbulkan persepsi pelanggan atas jasa yang diterimanya. Persepsi ini yang akan dibandingkan pelanggan terhadap ekspetasi dan disebut kualitas jasa.

Dari hasil penelitian dan pembahasan yang telah dilakukan maka dapat ditarik kesimpulan sebagai berikut: 1) Kuadran A merupakan prioritas utama ini dapat diketahui bahwa selama ini pengelola ECO Green Park belum memberikan jaminan atas kepuasan kepada pelanggan dan hal tersebut menjadi faktor yang penting menurut pelanggan yaitu mengenai petugas loket memberikan pelayanan secara cepat. 2) Kuadran kedua atau pertahankan prestasi, faktor-faktor yang memberikan jaminan atau dukungan dalam memberikan kepuasan pelanggan yaitu meliputi akses jalan menuju ECO Green Park mudah, ECO Green Park memiliki lapangan parkir yang luas, perusahaan memberikan informasi dengan tepat, pelayanan yang tepat / memuaskan oleh petugas, perusahaan memberikan informasi secara jelas, petugas cleaning service sigap membersihkan area wisata, petugas safetyguard siap melayani.

3) Kuadran ketiga atau prioritas rendah yakni mengenai pelayanan yang tepat/memuaskan oleh petugas, petugas memiliki pengetahuan luas ketika mereka menjelaskan kepada pengunjung seputar ECO Green Park, petugas secara konsisten bersifat sopan, petugas melayani dengan sungguh-sungguh dan sepenuh hati, pemberian pelayanan terhadap semua pengunjung tanpa pilih-pilih, kemudahan menyampaikan saran / keluhan. 4) Kuadran keempat atau berlebihan disini pihak manajemen ECO Green Park terlalu memperhatikan fasilitas pada kuadran ini namun demikian keberadaannya tidak terlalu menjadi pertimbangan bagi pengunjung. Faktot tersebut yaitu meliputi gedung dan bangunan ECO Green Park menarik, karyawan memiliki penampilan rapi, fasilitas umum ECO Green Park lengkap, petugas handal dalam mengoperasikan wahana.

\section{SIMPULAN}

Berdasarkan hasil penelitian dan pembahasan yang telah dilakukan maka dapat ditarik kesimpulan bahwaKuadran A merupakan prioritas utama ini dapat diketahui bahwa selama ini pengelola ECO Green Park belum memberikan jaminan atas kepuasan kepada pelanggan dan hal tersebut menjadi faktor yang penting menurut pelanggan yaitu mengenai petugas loket memberikan pelayanan secara cepat.

Kuadran kedua atau pertahankan prestasi, faktor-faktor yang memberikan jaminan atau dukungan dalam memberikan kepuasan pelanggan yaitu meliputi akses jalan menuju ECO Green Park mudah, ECO Green Park memiliki lapangan parkir yang luas, perusahaan memberikan informasi dengan tepat, pelayanan yang tepat / memuaskan oleh petugas, perusahaan memberikan informasi secara jelas, petugas cleaning service sigap membersihkan area wisata, petugas safetyguard siap melayani.

Kuadran ketiga atau prioritas rendah yakni mengenai pelayanan yang tepat/memuaskan oleh petugas, petugas memiliki pengetahuan luas ketika mereka menjelaskan kepada pengunjung seputar ECO Green Park, petugas secara konsisten bersifat sopan, petugas melayani dengan sungguh-sungguh dan sepenuh hati, pemberian pelayanan terhadap semua pengunjung tanpa pilih-pilih, kemudahan menyampaikan saran / keluhan.

Kuadran keempat atau berlebihan disini pihak manajemen ECO Green Park terlalu memperhatikan fasilitas pada kuadran ini namun demikian keberadaannya tidak terlalu menjadi pertimbangan bagi pengunjung. Faktot tersebut yaitu meliputi gedung dan 
bangunan ECO Green Park menarik, karyawan memiliki penampilan rapi, fasilitas umum ECO Green Park lengkap, petugas handal dalam mengoperasikan wahana.

\section{DAFTAR PUSTAKA}

Arikunto, Suharsimi, 2002,Prosedur Penelitian (Suatu Pendekatan Praktek), PT. Rineka Cipta, Jakarta.

Damanik J, Weber HF. 2006. "Perencanaan Ekowisata dari Teori ke Aplikasi”. ANDI Yogyakarta: Yogyakarta.

Gronroos, C.1992.Service Management and Marketing Lexington Books. Massachusettss, Toronto

Kotler, Philip. 2002. Manajemen Pemasaran di Indonesia: Analisis, Perencanaan, Implementasi dan Pengendalian. Salemba Empat. Jakarta.

Lovelock, Chistopher. H. dan Wright, Lauren K. (2005)Manajemen Pemasaran Jasa. P.T. Indeks Kelompok Gramedia.

Lupiyoadi, Rambat. 2001. Manajemen Pemasaran Jasa. Edisi Pertama. Salemba Empat: Jakarta.

Malhotra, Naresh, K, 2005, Riset Pemasaran; Edisi Empat, Jilid 1, PT. Indeks, Jakarta.
Margono. 2010. Metodologi Penelitian Pendidikan. Jakarta: Rineka Cipta.

Parasuraman, Valarie A. Z. and Berry. Delivering Service Quality. Mc Milan, New York, 2002, p.21.

Parasuraman, Zeithaml, A.V. dan Berry L.L. (1985), 'A Conceptual model of Service Quality', Journal of Retailing, Vol. 67: 420-450.

Sihite, Richart. 2000. Tourism Industry (Kepariwisataan). Penerbit SIC, Surabaya.

Sugiyono, 2011. Metode Penelitian Kuantitatif Kualitatif dan R\&D. Bandung: CV. Alfabet.

Sukmadinata, Nana Syaodih. 2011. Metode Penelitian Pendidikan. Bandung: Remaja Rosdakarya.

Supranto, Johaness. 2003. Metode Riset dan Aplikasinya Dalam Pemasaran. PT. Rineka Cipta. Jakarta.

Tjiptono, Fandy \& Candra Gregorius (2005)Service, Quality and Satisfaction. Penerbit Andi, Yogyakarta.

Tjiptono, Fandy, 2000. Manajemen Jasa, Edisi Kedua, Andy Offset. Jakarta.

Tjiptono, Fandy. 2001. Strategi Pemasaran. Edisi Pertama. Andi Ofset. Yogyakarta.

Widayat, 2004. Metode Penelitian Pemasaran. Edisi pertama. Malang. UMMPress 